\title{
Kinetic Analysis of the Reduction of Zinc and Iron Oxides from Dust and Slurry
}

\author{
S. G. Melamud ${ }^{a}$, V. A. Mal'tsev ${ }^{b}$, and B. P. Yur'ev ${ }^{c}$ \\ ${ }^{a}$ OOO NPRO Ural, Yekaterinburg, Russia \\ ${ }^{b}$ Yeltsin Ural Federal University, Yekaterinburg, Russia \\ ${ }^{c}$ Pervouralsk Branch, Yeltsin Ural Federal University, Pervouralsk, Russia
}

\begin{abstract}
The reduction of zinc and iron oxides from blast-furnace slurry and gas-purification dust at steel furnaces by heating with carbon is studied in physicochemical terms. Kinetic analysis reveals the optimal parameters of furnace reduction. Initial data are obtained for the development of a reduction technology for zinc and iron oxides.
\end{abstract}

DOI: $10.3103 / \mathrm{S} 0967091213020137$

The use of wastes from ferrous metallurgy is expanding in response to the growing scarcity and cost of ferrous and nonferrous metals and environmental deterioration. Thus, blast-furnace slurry and dust from gas-purification systems at steel-smelting furnaces contains zinc compounds, which sublimate on high-temperature treatment of pellets and metal scrap and are entrained with dusty gases. The zinc content is $1-3 \%$ in blast-furnace slurry and 5-20\% in electrofurnace slurry. The iron content in dust and slurry depends on the zinc content and is $30-50 \%$. The basicity $\mathrm{CaO} / \mathrm{SiO}_{2}$ of blast-furnace slurry is $1.2-1.3$, which is the value required for smelting. The slurry contains $10-12 \%$ solid carbon formed by the disintegration and entrainment of coke. The introduction of slurry and dust in sintering batch at metallurgical plants is limited by the accumulation of zinc in the blast-furnace lining, which consequently deteriorates.

To use zinc-bearing wastes, a separate system is needed for extraction and trapping of the zinc, while the remaining iron is returned to the metallurgical process. Since zinc sublimates above $1100^{\circ} \mathrm{C}$ only in metallic form and is present in slurry and dust as oxides, it is expedient to extract the zinc by reduction using carbon. In the present work, we investigate the kinetics of simultaneous iron and zinc reduction from dust and slurry pelletized with coke fines. The composition of such dust and slurry is different for different enterprises, as we see in the table.

The iron content in blast-furnace slurry is determined by the batch quality. At OAO MMK and OAO Ural'skaya Stal', where the batch consists mainly of local agglomerates with a high content of iron (56$58 \%)$ and pellets $(63-65 \% \mathrm{Fe})$, the slurry contains around $50 \% \mathrm{Fe}$. At OAO NTMK, with a considerably smaller proportion of pellets in the batch, the iron content is $45 \%$. At Serov Metallurgical Plant, where no pel- lets are used in the batch, and the sinter consists of relatively lean Bogoslovsk ore, it is no more than $30 \%$.

The zinc-oxide content in blast-furnace slurry from Serov Metallurgical Plant and OAO NTMK is higher $(5 \%)$, since the batch consists of complex zincrich Severopeschansk and Tagilo-Kushvinsk ores. KMA ore, whose concentrates are pelletized, has a lower impurity content and is free of zinc. Therefore, in slurry from blast furnaces whose batch contains 30$50 \%$ pellets (OAO MMK, OAO Ural'skaya Stal'), the zinc content is no more than $1 \%$.

The basicity $\left(\mathrm{CaO} / \mathrm{SiO}_{2}\right)$ of the blast-furnace slurry is close to the mean basicity of the batch $(1.2-1.3)$, and no fluxing is required. The fairly high content of solid carbon in the blast-furnace slurry $(\sim 10 \%)$ is due to the entrainment of the smallest coke fractions from the batch with the furnace's exhaust gases. The presence of reducing agent in the slurry permits significant reduction in consumption of the solid fuel (perhaps to zero) for the reduction of iron and zinc oxides when the pellet batch contains blast-furnace slurry. The main harmful impurity in the slurry is sulfur $(0.4-2.2 \%)$.

The grains of blast-furnace slurry are fairly large: no more than $48 \%$ of the grains are smaller than $0.063 \mathrm{~mm}$. Pellets are usually produced from materials in which $80-85 \%$ of the grains are smaller than $0.063 \mathrm{~mm}$. Hence, blast-furnace slurry requires grinding before pelletization. Thus, most of the blast-furnace slurry at Ural plants contains $1.5-3.0 \% \mathrm{Zn}, 30-$ $50 \% \mathrm{Fe}$, and around $10 \% \mathrm{C}$. Zinc must be removed before the slurry can be reduced to the blast furnace.

In comparison with blast-furnace slurry, steelsmelting slurry has a higher zinc content. In the dust from the DSP-80 arc furnace at the Serovsk plant and open-hearth dust at OAO NTMK, the zinc-oxide content is around 7\%; the corresponding figure for the Revda and Cherepovets plants is up to $25 \%$. The 
Mean chemical composition of zinc-bearing dust and slurry in ferrous metallurgy

\begin{tabular}{l|c|c|c|c|c|c|c|c|c|c|c|c|c}
\hline \multicolumn{1}{c|}{ Slurry or dust } & \multicolumn{2}{|c|}{ Content, wt \% } \\
\cline { 2 - 11 } & $\mathrm{Fe}_{\text {tot }}$ & $\mathrm{FeO}$ & $\mathrm{Fe}_{2} \mathrm{O}_{3}$ & $\mathrm{CaO}$ & $\mathrm{SiO}_{2}$ & $\mathrm{MgO}$ & $\mathrm{ZnO}$ & $\mathrm{PbO}$ & $\mathrm{S}_{\text {tot }}$ & $\mathrm{C}_{\text {co }}$ & $\begin{array}{c}\text { Calcina- } \\
\text { tion losses }\end{array}$ & $\mathrm{MnO}$ & $\Sigma_{\text {ox }}$ \\
\hline $\begin{array}{l}\text { Blast-furnace slurry } \\
\text { (OAO NTMK) }\end{array}$ & 44.5 & 8.9 & 53.7 & 6.6 & 5.7 & 1.2 & 3.4 & 0.02 & 0.40 & 10.9 & - & 0.4 & 91.2 \\
$\begin{array}{l}\text { Blast-furnace slurry } \\
\text { (Serov) }\end{array}$ & 29.7 & 13.3 & 27.6 & 15.7 & 11.5 & 1.8 & 4.7 & - & - & - & 16.1 & - & 90.7 \\
$\begin{array}{l}\text { Open-hearth dust } \\
\text { (OAO NTMK) }\end{array}$ & 53.2 & 0.5 & 75.4 & 0.1 & 0.6 & 0.8 & 7.0 & 0.5 & 2.2 & 0.1 & - & 1.3 & 88.5 \\
$\begin{array}{l}\text { Dust from DSP-80 } \\
\text { electrofurnace and } \\
\text { ladle-furnace unit } \\
\text { (Serov) }\end{array}$ & 43.7 & 3.5 & 58.5 & 8.2 & 10.0 & 2.5 & 6.7 & - & 0.6 & 1.0 & 3.3 & - & 94.3 \\
$\begin{array}{l}\text { Electrosmelting dust } \\
\text { (Revda) }\end{array}$ & 23.4 & 1.1 & 32.2 & 8.4 & 10.0 & 1.2 & 25.7 & - & 0.8 & 1.4 & 13.3 & - & 91.3 \\
$\begin{array}{l}\text { Electrosmelting dust } \\
\text { (Cheropovets) }\end{array}$ & 27.5 & 5.1 & 23.5 & 11.1 & 12.0 & 1.7 & 20.3 & - & 0.9 & 2.6 & 9.11 & - & 81.1 \\
$\begin{array}{l}\text { Blast-furnace slurry } \\
\text { (OAO MMK) }\end{array}$ & 49.0 & 10.0 & 58.9 & 6.8 & 9.4 & 1.8 & 0.6 & - & 0.6 & - & 8.9 & - & 97.0 \\
$\begin{array}{l}\text { Blast-furnace slurry } \\
\text { (OAO Ural'skaya }\end{array}$ & 50.4 & 10.0 & 60.9 & 6.4 & 7.2 & 2.0 & 1.5 & - & 0.3 & - & 9.7 & 0.8 & 98.5 \\
\hline Stal')
\end{tabular}

increased zinc content in steel-smelting dust may be attributed to the melting of zinc-bearing wastes at high temperatures, when the zinc sublimates and then is deposited in the cooled smoky gas.

The iron content in steel-smelting furnaces is determined, first, by the zinc-oxide content and, second, by the fluxes employed and the hot-metal content in the metal batch. Contamination of the dust with calcium oxides is associated with the use of lime, which is partially entrained with the gases. Silicon oxides appear in the dust on account of the contamination of scrap with sand or clay and primarily with use of hot metal containing $0.6-1.0 \% \mathrm{Si}$. On oxidation together with the carbon, the silicon enters the slag, some particles of which are entrained by the gases and trapped in the filters. Iron is mainly represented by $\mathrm{Fe}_{2} \mathrm{O}_{3}$.

The solid-carbon content in the steel-smelting dust is considerably less than in blast-furnace slurry and depends on the equipment employed. In open-hearth dust, where practically no carbon is incident on the surface of the slag bath, its content is no more than $0.1 \%$. In electrosmelting dust, the proportion of carbon is $1.0-2.5 \%$, since carbon electrodes are employed; on electrode combustion, particles are trapped at the filters. The granulometric composition of steel-smelting dust is significantly different from that of blast-furnace slurry. The content of $<0.05 \mathrm{~mm}$ particles is $92 \%$. The granulation of such materials in pure form is hindered by the strong adhesion of the particles and the formation of microgranules, which, in turn, adhere together to form berry-like granules. This may be prevented by adding large grains (0.05$0.10 \mathrm{~mm}$ ), such as blast-furnace slurry, coke, or coal.

Thus, most of the electrosmelting dust contains 5$20 \% \mathrm{Zn}, 30-45 \% \mathrm{Fe}$, and $1.0-2.5 \% \mathrm{C}_{\mathrm{so}}$. The sublimation of zinc from this dust requires the addition of carbon in the form of coke fines (coal) or blast-furnace slurry. That facilitates the formation of granules with a small surface. In view of the foregoing, electrosmelting dust is mixed with carbon-bearing material in experiments on reductive annealing. The experimental method is as follows.

To determine the temperature and time intervals characterized by the sublimation of zinc from dust and slurry, with simultaneous reduction of iron, we employ nonisothermal heating of sample tablets. That permits minimal consumption of material in obtaining the preliminary data required for full-scale experiments with pellets.

The samples are roasted in a Tamman tubular furnace (isothermal zone of height $60-80 \mathrm{~mm}$ ). The tablets are placed in a temperature-resistant wire basket, which may be moved within the corundum tube at specified speed. The specified heating (cooling) rate is maintained by selecting the required rate of descent (ascent) of the basket with the samples in the isothermal zone of the furnace. The furnace temperature is measured by a thermocouple in the isothermal zone. The sample temperature is monitored by means of a thermocouple in the basket. The atmosphere in the furnace is created by injecting high-purity helium 
upward through the bed. The necessary oxygen content is specified by adjusting the injection rate. In the zone where the main reductive processes occur (650$1250^{\circ} \mathrm{C}$ ), the oxygen content is maintained constant at $0.5-2.0 \%$.

In investigating the nonisothermal kinetics of iron kinetics and removing zinc, the samples are heated at a specified rate $\left(25-100^{\circ} \mathrm{C} / \mathrm{min}\right)$ to the required temperature and quenched in water. By chemical analysis of these samples, the degree of sublimation of zinc and the reduction of iron may be estimated. The degree of zinc sublimation is determined as the ratio of the mass of zinc removed from the sample to its initial content

$$
\alpha_{\mathrm{Zn}}=\left(M_{\mathrm{Zn}}^{\mathrm{in}}-M_{\mathrm{Zn}}^{\mathrm{re}}\right) / M_{\mathrm{Zn}}^{\mathrm{in}}=1-\left(M_{\mathrm{Zn}}^{\mathrm{re}} / M_{\mathrm{Zn}}^{\mathrm{in}}\right),
$$

where $\alpha_{Z n}$ is the degree of zinc removal, expressed as a fraction; $M_{\mathrm{Zn}}^{\mathrm{in}}$ and $M_{\mathrm{Zn}}^{\mathrm{re}}$ are the mass of zinc in the initial samples and residual zinc in the roasted sample, $\mathrm{kg}$.

The zinc content in the initial and roasted sample may be expressed as

$$
M_{\mathrm{Zn}}^{\mathrm{in}}=M_{\mathrm{in}} \mathrm{Zn}_{\mathrm{in}} ; M_{\mathrm{Zn}}^{\mathrm{re}}=M_{\mathrm{re}} \mathrm{Zn}_{\mathrm{re}},
$$

where $M_{\text {in }}$ and $M_{\text {re }}$ are the masses of the initial and roasted samples, $\mathrm{kg} ; \mathrm{Zn}_{\text {in }}$ and $\mathrm{Zn}_{\text {re }}$ are the zinc contents in the initial and roasted samples according to chemical analysis, wt \%.

The mass ratio of the initial and roasted samples may be calculated on the basis of total iron content according to chemical analysis, since these data are very accurate and iron simply changes its valency on reduction, without being lost from the material. In that case

$$
\mathrm{Fe}_{\mathrm{tot}}^{\mathrm{in}}=M_{\mathrm{Fe}}^{\mathrm{in}} / M_{\mathrm{in}} ; \mathrm{Fe}_{\mathrm{tot}}^{\mathrm{re}}=M_{\mathrm{Fe}}^{\mathrm{re}} / M_{\mathrm{re}}
$$

Since $M_{\mathrm{Fe}}^{\mathrm{in}}=M_{\mathrm{Fe}}^{\mathrm{re}}$, we find that

$$
M_{\mathrm{re}} / M_{\mathrm{in}}=\mathrm{Fe}_{\mathrm{tot}}^{\mathrm{in}} / \mathrm{Fe}_{\mathrm{tot}}^{\mathrm{re}} \text {. }
$$

Substituting Eqs. (2) and (4) into Eq. (1), we obtain a formula for determining the removal of zinc on the basis of chemical analysis of the initial and reduced samples

$$
\alpha_{\mathrm{Zn}}=1-\left(\mathrm{Zn}_{\mathrm{re}} / \mathrm{Zn}_{\mathrm{in}}\right) /\left(\mathrm{Fe}_{\mathrm{tot}}^{\mathrm{in}} / \mathrm{Fe}_{\mathrm{tot}}^{\mathrm{re}}\right) .
$$

The degree of reduction of the iron oxides is determined as the mass ratio of the oxygen bound in iron oxides that is removed the sample and the initial oxygen

$$
\alpha_{\mathrm{Fe}}=\left(M_{\mathrm{O}_{2}}^{\mathrm{in}}-M_{\mathrm{O}_{2}}^{\mathrm{re}}\right) / M_{\mathrm{O}_{2}}^{\mathrm{in}}=1-\left(M_{\mathrm{O}_{2}}^{\mathrm{re}} / M_{\mathrm{O}_{2}}^{\mathrm{in}}\right),
$$

where $M_{\mathrm{O}_{2}}^{\mathrm{in}}$ and $M_{\mathrm{O}_{2}}^{\mathrm{re}}$ are masses of oxygen bound in iron oxides in the initial and roasted samples, $\mathrm{kg}$.
The quantity of oxygen in the initial and roasted samples is

$$
\begin{aligned}
& M_{\mathrm{O}_{2}}^{\mathrm{in}}=M_{\mathrm{in}}\left(\mathrm{FeO}_{\mathrm{in}} \times 0.22+\mathrm{Fe}_{2} \mathrm{O}_{3 \mathrm{in}} \times 0.30\right) ; \\
& M_{\mathrm{O}_{2}}^{\mathrm{re}}=M_{\mathrm{re}}\left(\mathrm{FeO}_{\mathrm{re}} \times 0.22+\mathrm{Fe}_{2} \mathrm{O}_{3 \mathrm{re}} \times 0.30\right),
\end{aligned}
$$

where $\mathrm{FeO}_{\text {in }}, \mathrm{FeO}_{\text {re }}$ are the ferrous oxide contents in the initial and roasted samples, wt $\% ; \mathrm{Fe}_{2} \mathrm{O}_{3 \text { in }}, \mathrm{Fe}_{2} \mathrm{O}_{3 \mathrm{re}}$ are the ferric oxide contents in the initial and roasted samples, wt \%; 0.22 and 0.30 are stoichiometric coefficients for converting the $\mathrm{FeO}$ and $\mathrm{Fe}_{2} \mathrm{O}_{3}$ contents to the corresponding oxygen contents.

If we take the mass ratio of the initial and roasted samples from Eq. (4), we obtain

$$
=1-\frac{\left(\mathrm{Fe}_{\mathrm{tot}}^{\mathrm{in}} / \mathrm{Fe}_{\mathrm{tot}}^{\mathrm{re}}\right)\left(\mathrm{FeO}_{\mathrm{re}} \times 0.22+\mathrm{Fe}_{2} \mathrm{O}_{3 \mathrm{re}} \times 0.30\right)}{\left(\mathrm{FeO}_{\mathrm{in}} \times 0.22+\mathrm{Fe}_{2} \mathrm{O}_{3 \mathrm{in}} \times 0.30\right)} .
$$

The degree of reduction of iron is determined as the mass ratio of the metallic iron and total iron in the roasted sample

$$
\alpha_{\text {red }}=M_{\mathrm{re}} \mathrm{Fe}_{\text {red }}^{\text {tot }} / M_{\mathrm{re}} \mathrm{Fe}_{\mathrm{tot}}^{\mathrm{re}}=\mathrm{Fe}_{\mathrm{red}}^{\mathrm{re}} / \mathrm{Fe}_{\mathrm{tot}}^{\mathrm{re}},
$$

where $\mathrm{Fe}_{\text {red }}^{\mathrm{re}}$ and $\mathrm{Fe}_{\text {tot }}^{\mathrm{re}}$ are the contents of metallic iron and total iron in the roasted sample, \%.

On that basis, we may undertake the kinetic analysis of the combined reduction of zinc and iron oxides by means of pellets that consist of blast-furnace slurry $(80 \%)+$ OAO NTMK open-hearth dust (20\%). The pellet composition is as follows: $47.30 \mathrm{wt} \% \mathrm{Fe}_{\text {tot }}$; 7.09 wt $\% \mathrm{FeO} ; 3.03$ wt $\% \mathrm{Zn} ; 0.13$ wt $\% \mathrm{~Pb}$; and $0.80 \mathrm{wt} \% \mathrm{C}_{\mathrm{so}}$.

In Figs. 1 and 2, we show the results of kinetic analysis with different helium supply rates to the furnace space and different heating rates. When the helium supply rate is $2-3 \mathrm{~L} / \mathrm{min}$, air penetrates partially into the reaction zone by diffusion at the walls; the oxygen content above the pellet bed is $1.5-2.0 \%$. In this atmosphere, at a heating rate of $25^{\circ} \mathrm{C} / \mathrm{min}$, around $20 \%$ of the carbon has burned up at the beginning of reduction. The development of reduction above $800^{\circ} \mathrm{C}$, on the basis of gas liberation from the pellet pores, prevents oxygen access, and combustion stops. Three methods may be used to reduce the carbon combustion: (1) increase in the heating rate and decrease in the time from the onset of combustion $\left(500-600^{\circ} \mathrm{C}\right)$ to the onset of reduction $\left(800-850^{\circ} \mathrm{C}\right)$; (2) decrease in oxygen content in the reaction zone; (3) decrease in sample porosity, by replacing the pellets with dense briquets. In laboratory conditions, only two methods are used: the heating rate is increased to $100^{\circ} \mathrm{C} / \mathrm{min}$; and the helium supply rate is increased to $5-6 \mathrm{~L} / \mathrm{min}$ (Fig. 2). That reduces the oxygen content in the reaction zone to $0.5-1.0 \%$ and increases the rates of zinc sublimation and iron reduction (Figs. 1 and 2). 


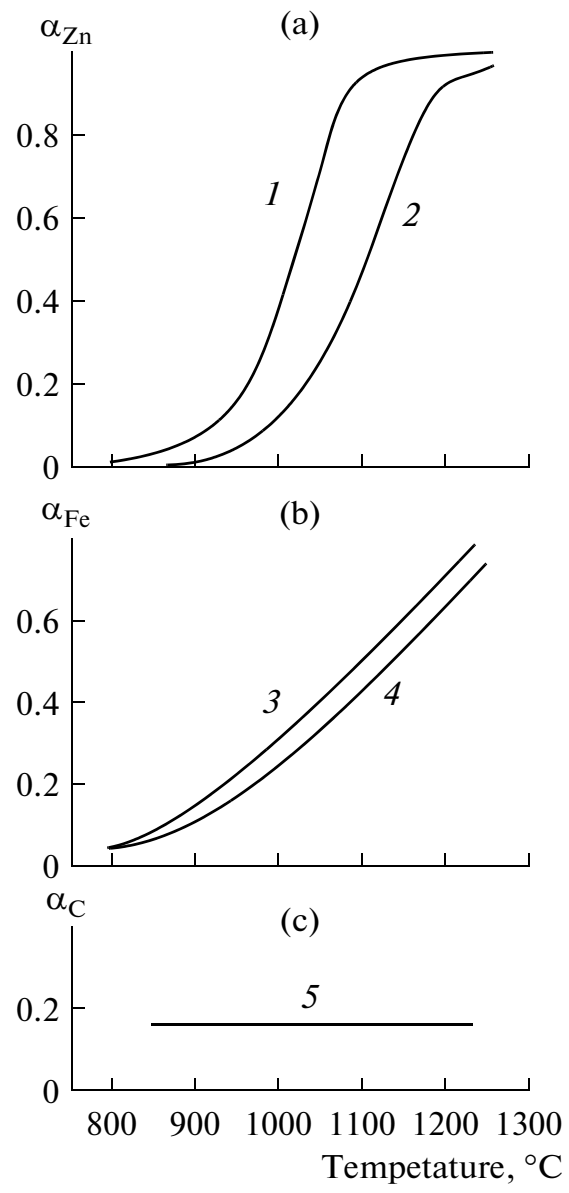

Fig. 1. Influence of the temperature to which blast-furnace slurry $(80 \%)+$ open-hearth dust $(20 \%)$ briquets are heated in a helium atmosphere (with $1.5-2.0 \% \mathrm{O}_{2}$ ) on the reduction of zinc oxides (a) and iron oxides (b) and the carbon burnup (c), with a heating rate of $25(1,3,5)$ and $100(2,4)$ $\mathrm{deg} / \mathrm{min}$.

We now consider the kinetics of zinc removal. At the minimum attainable oxygen content in the furnace $(0.5-1.0 \%)$, zinc removal begins at $800-900^{\circ} \mathrm{C}$ and is fastest at $1000^{\circ} \mathrm{C}$. In the interval $1100-1200^{\circ} \mathrm{C}$, sublimation slows, since practically $95-97 \%$ of the zinc compounds have already been reduced, and the reaction surface tends to zero. Obviously, in an isothermal profile, when the samples are placed in the zone at $1100^{\circ} \mathrm{C}$, the process is more rapid than at $1000^{\circ} \mathrm{C}$, in the absence of melting and slowing of the gas liberation.

Experimental results provide the basis for the description of the reaction between zinc oxide and carbon $[1,2]$

$$
\begin{gathered}
\mathrm{ZnO}+\mathrm{CO}=\mathrm{Zn}+\mathrm{CO}_{2} \\
\mathrm{C}+\mathrm{CO}_{2}=2 \mathrm{CO} .
\end{gathered}
$$

Accordingly, reduction occurs through the gas phase and does not depend on the contact of carbon and zinc-oxide particles. That is confirmed by experi-

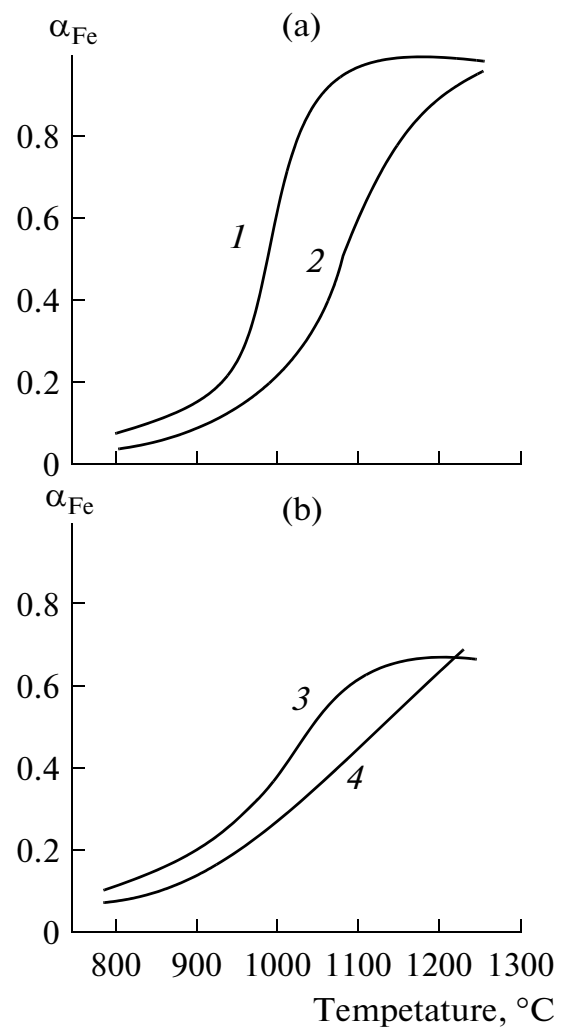

Fig. 2. Influence of the temperature to which blast-furnace slurry $(80 \%)+$ open-hearth dust $(20 \%)$ briquets are heated in a helium atmosphere (with $0.5-1.0 \% \mathrm{O}_{2}$ ) on the reduction of zinc oxides (a) and iron oxides (b), at a heating rate of $25(1,3)$ and $100(2,4) \mathrm{deg} / \mathrm{min}$.

ments on the reduction of a free mixture of reagents, pulverized briquets, and briquets obtained under different pressures. The small difference in reduction rates indicates that the oxide-carbon contact has little influence here. We also find that the reduction rate is related to the reducing-agent consumption. In particular, increase in the content of carbon increases the degree of reduction. This may be attributed not to increase in the number of contacts between solid particles but to increase in the partial pressure of the primary reducing agent in the pellet pores and proportional increase in the reaction rate in Eq. (11).

Note that, at different stages, not only the direct formation of metallic zinc by Eq. (11) but also its evaporation in the range $900-950^{\circ} \mathrm{C}$ may be determining [2]. Heating to the boiling point of zinc (1030$1130^{\circ} \mathrm{C}$ ) lifts the constraint on evaporation, of course, and the gasification of carbon in Eq. (12) becomes determining. In the section where reduction declines to zero, the determining process is the reduction of zinc by carbon monoxide, in kinetic conditions.

In iron ore, zinc oxide is present not only in free form but also as ferrite $\mathrm{ZnO} \cdot \mathrm{Fe}_{2} \mathrm{O}_{3}$. The following conclusions about the reduction of ferrite by solid carbon were established in [2]: in the reduction of zinc 
from ferrite, the rate is larger than in the case of structure-free oxide; the development of zinc reduction is largely controlled by the reduction of ferric oxide $\mathrm{Fe}_{2} \mathrm{O}_{3}$; the initial period of reaction is slow and is associated with the preferential reduction of iron oxides, after which the reduction rate of zinc increases. Intensification of the reduction of zinc from ferrite is due to activation by the metallic iron formed.

We now consider the reduction kinetics of iron oxides. It follows from Figs. 1 and 2 that the reduction of iron oxides is significantly slower than the removal of zinc. The greatest reduction rate of iron oxides is seen at $1100^{\circ} \mathrm{C}$, when the sublimation of zinc is practically over. With 8.8-9.0\% carbon in the pellets, typically, the degree of reduction is no more than $60 \%$, even above $1200^{\circ} \mathrm{C}$ (Fig. 2). In that case, the content of metallic iron is $30-40 \%$, with a total iron content of $60-65 \%$.

The low reduction rate of iron relative to zinc, even though the mechanism is similar, indicates obstructed diffusion of the reagents through the gas phase and the removal of the gaseous products through a layer of newly formed wustite and metallic iron phases. At the same time, judging from the products, the reduction of iron proceeds through a sequence of reactions

$$
\begin{gathered}
\mathrm{C}+\mathrm{CO}_{2}=2 \mathrm{CO} ; \\
\mathrm{Fe}_{2} \mathrm{O}_{3}+\mathrm{CO}=2 \mathrm{FeO}+\mathrm{CO}_{2} ; \\
\mathrm{FeO}+\mathrm{CO}=\mathrm{Fe}_{\text {red }}+\mathrm{CO}_{2} .
\end{gathered}
$$

For Eqs. (14) and (15), we require that $\mathrm{CO} / \mathrm{CO}_{2}=$ $(8-10) / 1$. That is ensured if the rate of carbon gasification exceeds the reduction. If the carbon content considerably exceeds the stoichiometric value, reduction will occur. If the carbon content is below $8-9 \%$, reduction is thermodynamically impossible.

\section{CONCLUSIONS}

It is important to utilization the waste products of ferrous metallurgy - in particular, blast-furnace slurry and gas-purification dust at steel furnaces, which contain zinc and iron oxides. The kinetic analysis of reduction by nonisothermal heating has been outlined. The combined reduction of zinc and iron oxides in blast-furnace slurry + open-hearth dust pellets by means of carbon has been investigated. The optimal parameters of this process have been determined: specifically, the solid-carbon content in the pellets, the oxygen content in the gas phase, the temperature interval of reduction, and the duration of the process. The necessary data for the development of combined reduction of zinc and iron oxides by carbon have been identified.

\section{REFERENCES}

1. Hammerschmidt, P., Hilbrands, P., Lachman, H.H., and Vogt, I., Removal of Zinc and Lead from Dust and Slurry in Sinter Production, Chern. Met., 1987, no. 1, pp. 25-30.

2. Tanutrov, I.N., Reduction of Zinc by Carbon, Izv. Akad. Nauk SSSR, Met., 1983, no. 1, pp. 11-15.

Translated by B. Gilbert 